\title{
Associative Meaning in Social and Cultural Context
}

\author{
Chunhua Mao \\ Hunan Vocational College of Commerce, Changsha, 410205, China \\ sunia_mao@sina.com
}

Keywords: Associative Meaning; Social and Cultural Context; Communicative Effect

Abstract. This paper discusses the associative meaning in social and cultural context. It introduces the seven types of meaning and its definition on associative meaning put forward by Leech. Associative meaning is highly characterized by culture and influenced greatly by society. Words sharing the same meaning may have their respective associative meaning in different social context, and produce different communicative effect. Therefore, exploring the associative meaning is helpful in cross-culture communication.

\section{Introduction}

Newmark once said, "Language is partial reflection of a culture. Culture is an aspect of the society in language.” Therefore, language is the carrier of culture while culture is the connotation of language. Each language, with long history and varied cultural implication, is a product of the development of an ethnic culture. Each country or nation has its particular evolution history, social system, eco-environment, religions, beliefs and traditions, and consequently each language has its specific culturally-loaded words to reflect these conceptions and things. This paper is going to discuss the non-referential meaning-the associative meaning, and its communicative functions.

\section{Development of Semantics in History}

The subject concerning the study of meaning is called SEMANTICS. Specifically, semantics is the study of the meaning of linguistic units, words and sentences. Meaning has always been a central topic in human scholarship, though the term "semantics" has only a history of over a hundred years. There were discussions of meaning in the works of Greek philosopher Plato as early as in the fifth century before Christ. In China, Lao zi had discussed similar questions even earlier. That fact that over the years numerous dictionaries have been produced with a view to explaining the meaning of words also bears witness to its long tradition.

According to Hu Zhuanglin and Jiang Wangqi, a distinction is usually made between two different approaches to meaning. The approach in which more attention is paid to the meaning of linguistic units themselves, words and sentences in particular, may be called Linguistic Semantics. The approach is more concerned with the relationship between linguistic expressions and the phenomena in the world to which they refer. The conditions under which such expressions can be said to be true or false, may be called Philosophical Semantics or Logical Semantics. It was in his book ESSAYON SEMANTICS published in 1897, that Breal first used the the term in its present-day sense as the science of meaning.Its English version came out in 1990.

Meaning can also be studied from different points of view with various approaches. LiFuyin and Koenraad Kuiper have selected 13 significant approaches and look at meaning in terms of 6 levels. See the following table:

\begin{tabular}{|l|r|r|r|r|r|r|}
\hline \multicolumn{1}{|c|}{ Level } & Morphemes & Words & Phrases & Clauses & Sentences & Texts \\
\hline Phonetic Approach & & & & & & \\
\hline Grammatical Approach & + & + & & + & + & + \\
\hline Logical Approach & + & + & + & & + & \\
\hline Philosophical Approach & & + & & + & + & \\
\hline
\end{tabular}




\begin{tabular}{|l|r|r|r|r|r|r|}
\hline Pragmatic Approach & & + & & & & + \\
\hline Cognitive Approach & & & & & & \\
\hline Functional Approach & & + & & & & + \\
\hline Stylistic Approach & & & & & & \\
\hline Social Approach & & + & & & & \\
\hline Anthropological Approach & & + & & & + & + \\
\hline Semiotic Approach & & + & & & & \\
\hline Psychological Approach & + & + & & & & \\
\hline Historical Approach & + & + & & & & + \\
\hline
\end{tabular}

From the angle of the six levels, Li Fuyin and Koenraad Kuiper did research according to this frame. In the study of meaning, semantics assumes an important position in the study of language. We make sounds, words, and sentences in order to mean something, to express some meaning. It is more difficult to study the sounds and forms of words and sentences. At the present, semantics is the least known area in linguistics, compared with phonetics, phonology, morphology and syntax.

\section{Seven Types of Meaning.}

One difficulty in the study of meaning is that the word "meaning” has many different meanings. In 1974, An English linguist named Geoffery Leech published his famous Semantics. It symbolized that the study on meaning had broken the limits of traditional linguistics. Leech had put the study of meaning under the social cultural background and emphasized the communicative functions of meaning. In a more moderate tone, G. Leech recognized 7 types of meaning in his Semantics, as follows;

Table 2

\begin{tabular}{|l|l|}
\hline Type & Definition \\
\hline Conceptual meaning & Logical, cognitive, or denotative content \\
\hline $\begin{array}{l}\text { Connotative } \\
\text { meaning }\end{array}$ & What is communicated by virtue of what language refers to \\
\hline Social meaning & What is communicated of the social circumstances of language use \\
\hline Affective meaning & What is communicated of the feelings and attitudes of the speakers lwriter \\
\hline Reflected meaning & $\begin{array}{l}\text { What is communicated through association with other senses of the same } \\
\text { expression }\end{array}$ \\
\hline Collective meaning & $\begin{array}{l}\text { What is communicated through association with words, which tend to } \\
\text { occur in the environment of and other word }\end{array}$ \\
\hline Thematic meaning & $\begin{array}{l}\text { What is communicated by the way in which the message is organized in } \\
\text { terms of order and emphasis }\end{array}$ \\
\hline
\end{tabular}

Leech says that the first type of meaning-conceptual meaning-makes up the central part. It is "denotative" in that it is concerned with the relationship between a word and the thing it denotes. In this sense, conceptual meaning overlaps to a large extent with the notion of REFERENCE, but the term" connotative" used in the name of the second type of meaning is used in a sense different from that in philosophical discussions.Philosophers use CONNOTATION, opposite to DENOTATION to mean the properties of the entity a word denotes. For example, the denotation of HUMAN is any person such as John and Mary, and its connotation is "biped", "featherless", "rational", etc. In Leech's system, however, as is the case in daily conversation, "connotative" refers to some additional, especially emotive, meaning. The difference between politician and statesman, for example, is connotative in that the former is derogatory while the latter is favourable.This type of meaning and the following four types are collectively known as associative meaning in the sense that an elementary associationist theory of mental connections is enough to explain their use.The last type,thematic meaning, is more peripheral since it is only determined by the order of the words in a sentence and the different prominence they each receive. But even when "meaning"is understood in 
the first sense above,there are still different ways to explain the meaning of a word.In everyday conversation,there are at least the following four ways.Suppose you do not know the word desk,and ask what it means.One may point to the object the word stands for,and answer"This is a desk." Alternatively he may describe the objects as "a piece of furniture with a paraphrase it, saying that "a desk is a kind of table, which has drawers." If he is a teacher of English, then he may more often than not give you its Chinese equivalent. The first method is usually used by adults to children, since their vocabulary is small and it is difficult to explain to them in words. The second and the third are the usual methods adopted in monolingual dictionaries, which sometimes may also resort to the first by illustrating with pictures.

\section{Associative Meaning in Social and Cultural Context}

The associative meaning can directly or indirectly reflect the cultural concept of a certain linguistic community. In language, we still have two other types of words: taboo and euphemism. From their associative meaning, we can see the direct influence of social culture on semantics. A hundred years ago in Western Europe, people of the upper class were so touchy about the relationship between men and women that some funny words were created. For instance, "I have bought an indescribable (meaning undergarment s)", and “one-must-not-metion-ems; unspeakbles; sit-upons".Pregnancy is a casual topic in the present society. However, it took the English society 100 years to speak out the word"pregnant "directly. The followings are some euphemisms for pregnancy listed by an American humor writer .For example:

She is in an interesting condition. (1880)

She is in a delicate condition. (1895)

She is knitting little bottees. (1910.)

She is in the family way. (1920)

She is expecting. (1935)

She is pregnant. (1956)

Among English words, terms of color make up a group of words that are particularly rich in cultural associations. Linguist Ali Mazuri studied the associative meaning of Black by English literal material. He thought that black was usually associated with sin, nothingness and death. For example , in the poem Paradise Lost written by Milton, Satan and other angles are all white, but after they offended God and were exiled from heaven to hell, they were all burned into black. They became black evils. Western psychologists tested preference of color on 2000 students in London, and the result showed that the preference of color in order is red, green, yellow and black. So black was the most unpopular color among them.

In both Chinese and English black is associated with negative qualities. For example black market, blacklist, black sheep, blackmail, etc. To the term“black box"is somewhat different. At first sight we may assume it is somthing black. However, it is orange and yellow. It is called“black box"because black is a symbol of "calamity" and"misfortune”. The choice of this term is connected to meaning , not color . The"black hole"in astronomy can be associated with"the hole is black". In fact, it is not true. It actually refers to the phenomenon of a celestial body. Culture should be considered in such translation. Culture belongs to a community, and is not held by only one individual but born with individuals. People learn culture through various social activeities.

In social lives, people can acquire their national culture that used to be unfamiliar to them, so they also can naturally obtain the foreign nations'unfamiliar culture in the process of communicating different cultures. For example, with increasing cross-cultural exchange, when hearing First Lady in news, Chinese people don't have any doubt about how many wives the President really has. “Jingju”is a typical traditional art in China, in western countries this term is expressed as "Beijing Opera". This shows that every nation is learning others'culture and culture can be acquired through the communication in society. 


\section{Communicative Effect Produced by Associative Meaning}

The referential meaning or the conceptual meaning of "relief"and"insurance"is the same , but because the ways of distribution were different, the people's attitudes towards the 50 dollars in the two towns were different too. In other words, the two words “relief "and"insurance" arouse different associations. It is the associative meaning that caused the families in the two towns to have different feelings and experiences. In daily conversations, synonyms which have different associative meanings usually cause a“communicative barrier”in the same way. In English , many words which are closely related to ethnic groups and political issues, have a very clear conceptual meaning , but a different associative meaning, e. g. yanks, wops, Japs, reds, pigs . All these words convey typical derogative meanings. When the associative meaning which surpasses the conceptual meaning becomes the major content of its verbal information, it is difficult to communicate effectively. The reason for the success of some advertisements is because the associative meaning of the words has been fully and elaborately expressed. See the following advertisement:

In this artificial world , the world of concret, steel and synthetics - - - the chemical , the man-made, the mechanica , monotone world of the city , there are still beautiful natural things to make living better. Wool is one of $t$ hem. Wool lives .

In this advertisement, so many words like artificial, concrete, steel, synthetics, chemical, man-made, mechanical, monotone etc. , create such a cold situation that readers may have an unpleasand association. Under this circumstance, the two rich words "beautiful and natural "make people think of the delicate fragrance of nature. Then the author talks about the advertised goods -wool. This would naturally induce people to think of something very soft and affectionate. This is no doubt the secret for the success of the advertisement .

\section{Summary}

In a word, the associative meaning of language is closely related to the social culture. In verbal communication, it's easy to get the conceptual meaning, but the conveyed cultural information, i.e., the associative meaning which is attached to the conceptual meaning, is not easy to accept due to the strictness of the dual cultural differences. Therefore, it is necessary to recognize cultural characteristics and convey the language and the cultural information hidden in the words. Only by concrete and adequate contrast between two cultures, can it be possible to achieve relative translation equivalence. So for us, it is important to pay more attention to the relationship between language and culture.

\section{Acknowledgement}

I would like to extend my thanks to my husband for his support in the work and editing of this paper and also appreciate the anonymous referees who gave advice on this paper. All remaining errors are my own. This research was supported by the Project for Science Research in College and University Funded by the Education Department of Hunan Province (10C0205).

\section{References:}

[1]Eugene A.Nida, Language, Culture, and Translating, Shanghai Foreign Education Press (1993)

[2] Geoffery Leech, Semantics , Shanghai Foreign Educational Press(1974)

[3] Hu Zhuanglin, Linguistics: A Course Book, Beijing University Press(2001).

[4] Li Fuyin, Koenraad Kuiper. Semantics: A Course Book, Shanghai Foreign Education Press (1999).

[5] Newmark, Peter. About Translation. Foreign Language Teaching and Research Press(2006). 